\title{
A Noção de Pessoa Ocidental como Fundamento do Amor Romântico
}

\author{
Rhuann Fernandes ${ }^{\mathrm{a}}$ \\ Claudia Barcellos Rezende ${ }^{\mathrm{b}}$
}

Resumo: Partindo da ideia de que as experiências emotivas são articuladas às dinâmicas sociais e a significados culturais, a proposta deste artigo é questionar a noção de pessoa ocidental e o seu pressuposto de universalidade no que se refere às emoções, em especial o amor. Nesse sentido, indagamos se noções outras de pessoa produzem concepções distintas sobre esse sentimento. Com isso, desnaturalizamos o conceito de pessoa que é familiar nas sociedades ocidentais e, ao mesmo tempo, evidenciamos como essa categoria foi determinante para noção de amor romântico, ainda presente no senso comum ocidental, sendo ilustrado por filmes, novelas, músicas e desenhos.

Palavras-chave: Amor, Emoções, Indivíduo, Pessoa.

No início da pandemia de COVID-19, nos deparamos com um artigo do filósofo germano-coreano Byung-Chul Han, publicado no jornal El Pais, que nos inquietou. ${ }^{1}$ Nele, Han fala, a partir de um

a Mestrando em Ciências Sociais (PPCIS/UERJ). Pesquisador do Núcleo de Estudos Transdisciplinar de Colonialidade(s), Emoções e Relações de Poder (NECERP). Email: rhuannfernandes.uerj@gmail.com.

b Professora Titular do Departamento de Antropologia (UERJ). Pesquisadora do CNPq, com bolsa de produtividade nível1 D. Email: cbrezende65@gmail.com. 
breve levantamento de dados, da dificuldade de países ocidentais tratarem do coronavírus em comparação aos países asiáticos que foram mais efetivos, em virtude das distintas predominâncias de 'tradições culturais'. No mundo euroamericano, de acordo com o filósofo, nós temos o indivíduo como cerne em que o ideal de liberdade é o valor supremo. A obrigatoriedade do uso da máscara torna-se argumento para 'perda de direitos'. Em contraste, nos estados asiáticos, apesar de alguns assumidamente liberais, o que se observa é uma 'mentalidade autoritária', em que as pessoas confiam mais no Estado e o termo 'esfera privada' não faz tanto sentido. Assim, a vigilância digital para conter o vírus, por exemplo, não seria um problema, já que inexiste a lógica de 'proteção de dados'.

Segundo Han, o exemplo da China é singular, pois a vida cotidiana está submetida à observação constante. Foi demonstrada para o mundo uma infraestrutura de vigilância digital profundamente eficaz para combater a epidemia. Isso só foi possível, conforme o filósofo, pelo fato de que na Ásia impera o coletivismo e não há um individualismo acentuado, enquanto para os euroamericanos o individualismo se amarra ao costume de andar com o rosto descoberto e, ironicamente, os únicos que estão mascarados são terroristas e criminosos.

Essa demonstração de 'diferença cultural' realizada por Han, apesar de conter várias generalidades, trouxe-nos vários questionamentos. A principal questão que suscitamos é entender como o conceito de pessoa individual no ocidente moderno é fundamental para a materialização da noção de amor, mais especificamente o amor romântico e o modo como essa noção foi disseminada e tornada hegemônica, a partir do colonialismo.

Desde o final do século XVIII, constata-se a emergência do amor romântico, no qual se incorporaram pela primeira vez 'amor' e 'liberdade', ambos julgados como estados normativamente ambicionáveis (Giddens 1993). Com a modernidade, o casamento passou a ser visto como possível consequência do amor erótico-sexual em uma versão romantizada, na qual teríamos um percurso clássico e padronizado: 
depois de se apaixonar, namora-se, noiva-se e, por fim, estabelece-se o pacto monogâmico central, que é o casamento. Essa instituição pressupõe a obrigatoriedade de fidelidade e eternidade que, quando combinadas, produzem a noção normativa de exclusividade afetivo-sexual. Isto é, só é possível amar uma pessoa de cada vez. Esses seriam os princípios do amor para os ocidentais, disseminado para outras regiões do globo com os processos de dominação de povos não europeus (Macfarlane 1990).

O modelo monogâmico tradicional e heteronormativo presente nas sociações ocidentais modernas tem como principal lema - como verificado em novelas e filmes - encontrar 'o verdadeiro amor da vida', único de preferência, e manter a relação apenas com ele, quiçá eterna. As 'origens' culturais dessas convicções e exigências de ordem moral respaldam-se, paradoxalmente, nos argumentos de ordenação social e poder, pautados por ampliação de riquezas e perpetuação de patrimônio. O 'mito do amor romântico' no ocidente se sustenta nos princípios de exclusividade e fidelidade, nos quais a monogamia é apresentada como única, espontânea e natural formato de relacionamento humano. Para concretizá-la, deve-se ser atingido por uma ligação cósmica e verdadeira (Vainfas 1992).

Surge-nos, a partir dessa reflexão, uma indagação elementar: outras noções de 'pessoa' produzem visões diferentes sobre o 'amor'? De imediato, afirmamos que sim, pois a definição da noção de pessoa perpassa inteiramente à maneira pela qual nos relacionamos com o meio social (Strathern 2014), estando as experiências emotivas articuladas às dinâmicas sociais e a significados culturais (Lutz 1986). Contudo, há inúmeras nuances que pretendemos explorar neste artigo a partir deste questionamento. Assim, desnaturalizamos o conceito de pessoa que é familiar nas sociedades ocidentais, expondo seu lócus e os seus limites, entendendo-o como intrínseco ao referencial moderno. Nesse sentido, exploramos as possibilidades de tratarmos dessas categorias aproximando-as criticamente daquilo que Gilles Deleuze (1974) compreende como 'devir moderno', pelo qual se apreende uma das prin- 
cipais ilusões nessas sociedades: a eleição do indivíduo como critério principal para a criação e o julgamento dos saberes.

Para ultrapassar tal atitude e descentralizá-la como eixo, interrogamos no primeiro tópico deste trabalho a noção de 'sociedade' e sua obsolência, bem como a necessidade de revisitarmos a categoria 'indivíduo' e realizarmos o movimento de desestabilizá-la. No segundo, terceiro e quarto tópico explicamos como chegamos à noção de sujeito cognoscente, para, na quinta parte do trabalho, demonstrar que essa percepção foi imprescindível para o surgimento e afirmação dos valores morais do amor moderno, predominante atualmente nas sociedades ocidentais. Nesta análise, discutimos também a formação da etnopsicologia euroamericana e de um senso comum ocidental acerca do amor e outras emoções. Por fim, no último ponto questionamos se essa ideia de amor pode ser 'localizada' apenas no ocidente, trazendo algumas contribuições teóricas para repensar essa afirmação particularista.

\section{Os caminhos percorridos}

Ao analisarmos a história das ciências sociais e a sua institucionalização, notamos que os conceitos de 'sociedade' e 'indivíduo' foram fundamentais para a formação e consolidação da área, já que o objetivo inicial era comunicar a importância da dimensão das relações sociais na vida e no pensamento humano. As críticas realizadas por Marilyn Strathern (2014), ao problematizar o conceito de 'sociedade', revelam a importância das revisões de conceitos, uma vez que esses podem esconder relações de poder. De fato, durante muito tempo, a antropologia se inspirou no mito da 'sociedade primitiva', produzindo visões etnográficas românticas, cujas concepções clássicas precisam ser relativizadas em seus limites modernos. ${ }^{2}$

Embora existam múltiplas discordâncias e reformulações dos conceitos ao longo do tempo, a autora diz que a ideia de 'sociedade', por exemplo, é concebida como um todo homogêneo, pronto e estático, 
empregada como se fosse uma entidade autônoma e utilizada como dispositivo retórico, "[...] como uma maneira de dar acabamento à narrativa etnográfica [...]” (Strathern 2014: 236). Ao apresentar uma crítica do antropólogo britânico Edmund Leach (1910-1989) sobre o vício do pensamento dicotômico, Strathern (2014) afirma que o conceito de 'sociedade', em geral, é utilizado por comparação, assumindo o sentido de uma entidade abstrata em que a teoria procuraria explicar sua relação com outras entidades.

Essa explicação, porém, não criaria uma relação a algo, mas uma oposição, devido à abstração do conceito como um objeto intangível, estagnado e coisificado. É nesse sentido que a personificação da oposição entre 'indivíduo' e 'sociedade' foi desenvolvida. Nela, extinguem-se e invisibilizam-se outras relações, não se reconhecendo a diversidade de formas sociais. Assim, "em vez de considerar a sociedade como inerente à definição da noção de pessoa, define-se sociedade em oposição à indivíduo” (Strathern 2014:236). Nessa perspectiva, Strathern afirma que, num primeiro momento, a 'sociedade' foi entendida como algo posterior, sendo resultado da interação prévia entre os 'indivíduos'. Esses agentes submeteriam suas ações a uma regulação fruto do convívio social, isto é, a vida em 'sociedade'. Num segundo momento, desenvolveu-se a ideia de uma 'sociedade' autônoma, que existe para além dos seres humanos, em que esses seriam apenas membros, o que gerou uma noção de 'sociedade' como constituída por grupos de indivíduos.

Em ambos os casos, a 'sociedade' é definida como coisa. Assim, tanto a noção de 'indivíduo' quanto a de 'sociedade' parecem sempre precipitar um ao outro. Dessa forma, desconsidera-se que as práticas sociais são um meio do comportamento humano e não podem ser opostas a ele. Em contraste, para evitar essa 'paródia terrível', a autora afirma que não precisamos mobilizar o conceito de 'sociedade', posto que não precisamos compará-lo com o conceito de 'indivíduo'. Nessa perspectiva, ela propõe o conceito de 'socialidade', que em sua definição é uma "[...] matriz relacional que constitui a vida das pessoas e até 
mesmo 'sociedades' como um pluralismo de uso prático, representativo de populações com organizações distintas” (Strathern 2014:236). Ou seja, os conceitos de 'indivíduo' e 'sociedade' devem ser reconstruídos a partir de um ponto de vista dialético, pois eles se concebem, já que "as relações sociais são intrínsecas, e não extrínsecas, à existência humana” (Strathern 2014:239).

Desse modo, evitaríamos a 'verdadeira tragédia', que é o anseio de instrumentalizar um polo dessa dicotomia e expor o 'indivíduo' em desacordo à 'sociedade'. Ela faz referência à tragédia pelo fato de que a oposição desses conceitos camufla formações sociais e relações de poder, assistindo interesses comerciais e políticos. Entretanto, para a autora, uma das piores consequências foi instaurada: a invenção da "[...] própria sociedade como entidade" fez "[...] as relações parecerem secundárias e não primárias para a existência humana" (Strathern 2014:239). ${ }^{3}$

No fim, Strathern (2014) oferece a possibilidade de questionar os conceitos socialmente naturalizados e as suas consequências. Clifford Geertz (1997) afirma, a partir dos três universos simbólicos que estudou (marroquino, balinês e javanês), que a finalidade de sua investigação e da análise antropológica, em geral, é o entendimento de como as pessoas que habitam as socialidades se definem. Isto é, em seu caso, entender o estilo de 'eu' marroquino, balinês e javanês. "[...] Para entender as concepções alheias é necessário que deixemos de lado nossa concepção, e busquemos ver as experiências de outros com relação à sua própria concepção do eu" (Geertz 1997:91). O autor identifica que:

"[...] para nós ocidentais, a concepção da pessoa como um universo cognitivo e motivacional delimitado, único, e mais ou menos integrado, um centro dinâmico de percepção, emoção, juízos e ações, organizado em uma unidade distinta e localizado em uma situação de contraste com relação a outras unidades semelhantes, e com seu ambiente social e natural específico, nos pareça correta, no contexto geral das culturas do mundo ela é uma ideia bastante peculiar" (Geertz 1997:90-91). 
Desse modo, precisamos, como propõe Geertz (1997), evitar a utilização da categoria de indivíduo moderno para apreender a acepção de outros modus vivendi, que seria a tarefa antropológica por excelência.

\section{A noção de pessoa no ocidente}

Mauss (2003) reitera que a definição de pessoa, de humano, é um fenômeno universal, desenvolvido entre todos os grupos sociais, apesar das inúmeras diferenças entre eles. Entretanto, essa ideia não pode ser considerada como um dado natural a priori, como algumas áreas científicas insistem em fazer ao tratar os seres humanos como produtos de sua neuroquímica ou sua neurobiologia. A noção do que é uma pessoa deve ser observada como variável e não pode ser tratada como categoria onipresente, como algo aparentemente pronto, sem levar em conta o contexto cultural.

Mauss argumenta que a ideia de pessoa individual como ente sagrado, cognoscente, possuidor de uma força moral e dotado de direitos naturais só pode ser pensada a partir do ocidente. Ao falar da "pessoa" como fato moral, ele faz uma associação ao sentido jurídico que a legitima, baseado numa herança latina de Direito. É “[...] um sentido de ser consciente, independente, autônomo, livre, responsável” por suas ações (Mauss 2003:390-391). Nessa lógica, a consciência moral introduz a consciência na concepção jurídica do Direito. Essa ideia será utilizada e massificada pelo cristianismo, a partir da Idade Média, que ofereceu "uma base metafísica mais segura" para noção de pessoa.

"Foram os cristãos que fizeram da pessoa moral uma entidade metafísica, depois de terem sentido a sua força religiosa. Nossa própria noção de pessoa humana é ainda fundamentalmente a noção cristã. [...] Ocorre a passagem da noção de persona, homem investido de um estado, à noção de homem simplesmente, de pessoa humana" (Mauss 2003:392, grifo do autor).

De acordo com Mauss (2003), surge aqui a elaboração do indivíduo como valor metafísico e moral, na corporificação daquilo que 
viria a se constituir como sistema religioso cristão, que faz emergir a ideia de pessoa como substância racional irredutível e individual. Contudo, ele argumenta que essa substância racional indivisível só estaria completa a partir do Renascimento, com os filósofos modernos, que a transformaria numa consciência e uma categoria, forma fundamental para agir e pensar. De acordo com o autor, até meados da Renascença, essa noção de indivíduo não existia.

"A noção de pessoa haveria de sofrer ainda uma outra transformação para tornar-se o que ela se tornou há menos de um século e meio, a categoria do Eu. Longe de ser a ideia primordial, inata, claramente inscrita desde Adão no mais fundo de nosso ser, eis que ela continua, até quase o nosso tempo, lentamente a edificar-se, a clarificar-se, a especificar-se, a identificar-se com o conhecimento de si, com a consciência psicológica" (Mauss 2003:394, grifo do autor).

A partir desse movimento, tem-se a edificação da concepção de 'eu' enquanto indivíduo, sujeito com consciência psicológica e dotado de razão a ponto de repensar e refletir a si mesmo. Nesse momento, pessoa e consciência se equivalem e todo fato de consciência é um fato do 'eu', em que cada sujeito tem um próprio 'eu'. Assim, essa noção passou a integrar a realidade e inclusive tornou-se seu centro. Entretanto, tal exercício só seria possível em plena liberdade. Por esse motivo, a ênfase e a defesa da liberdade individual como precursora para o desenvolvimento da consciência individual, pois tudo passa a ser orientado pelo indivíduo e do seu lugar.

Essa defesa já havia encontrado ecos entre os protestantes, na Reforma Religiosa, na qual uma das reivindicações era o "direito de comunicar-se [...] com Deus, de ser um sacerdote para si mesmo, de ter um Deus interior" (Mauss 2003:395) que tinha como base a noção de que pessoa era igual ao 'eu' e 'eu' igual à consciência. É nessa direção que os valores primordiais da burguesia, os quais expressam uma revolução das mentalidades no que se refere a pensar o 'eu' no ocidente ficam consagrados. Conforme Mauss (2003), a categoria de pessoa é cultural, pois, ao longo da história e das socialidades, a ma- 
neira de se entender enquanto pessoa se transforma. Nessa sequência, a existência da concepção de pessoa é universal, mas sua definição é variável, sendo entendida como condição ontológica que sugere diferenças profundas entre os grupos humanos. Quer dizer, os conceitos e as categorias surgem numa formação social específica, na qual se atribui e projetam particularidades a eles. Não à toa, Mauss (2003) faz o movimento histórico de analisar e comparar a concepção de pessoa para alguns povos originários em relação ao conceito de persona e em outras regiões, como na China e na Índia, entendendo que apenas entre os ocidentais desenvolveu-se a noção de pessoa como ser individual e psicologizado.

Nessa mesma linha argumentativa, o antropólogo francês Louis Dumont (1985) sustenta que a pessoa individual, tal como concebida no mundo ocidental, é uma figura recente. A gênese mais próxima da pessoa que nós somos, para ele, está no Renascimento e assume valor sui generis. Entretanto, Dumont (1985) não busca sua origem nesse período histórico, mas sim nas heranças do judaico-cristianismo, pelas quais o Renascimento apenas assiste à afirmação do novo valor da pessoa, interpretada como indivíduo, partindo a teia holística que até aquele momento a manteve.

Diante disso, o autor analisa as características do individualismo moderno, que é marcado por sua 'intramundanidade'. Em sua interpretação, o indivíduo, no sentido de ser moral autônomo e independente, desenvolveu-se a partir do mundo medieval, conquanto se possa dizer que "algo do individualismo moderno está presente nos primeiros cristãos” (Dumont 1985:36). Isso não significa que, em outras sociações, não exista a possibilidade de individualização.

$\mathrm{Na}$ realidade, o autor chama atenção para a noção de indivíduo como valor que forma a ideologia contemporânea ocidental. Então, como a teoria antropológica deve lidar em situações nas quais o indivíduo não é um valor? Dumont (1985) observa que, quando se fala de 'indivíduo', é preciso distinguir o 'sujeito empírico', unidade e átomo da espécie, encontrado em toda e qualquer sociação; do 'indivíduo' 
como ser moral, concebido como independente, autônomo e, assim, essencialmente não social, tal como encontrado sobretudo em nossa ideologia moderna de ser humano e de 'sociedade'.

Nesse sentido, há sociedades para as quais a diferença entre os indivíduos é reconhecida antes pela sua posição no interior do grupo do que pela singularidade absoluta, anterior à vida social, tal como a moderna ideologia individualista pretende. Para Dumont (1985), investigar contextos para além do mundo euroamericano requer o movimento de lidar com questões históricas e culturais outras de modo singular. Por essa razão, o autor afirma que o 'indivíduo' seria uma noção de pessoa específica, elaboração do ocidente moderno, no qual os antropólogos não poderiam se basear para analisar outros contextos culturais.

\section{O sujeito psicológico}

"A psicologia é somente uma fina película na superfície do mundo ético no qual o homem moderno busca sua verdade - e a perde" (Michel Foucault 2000).

A posição do indivíduo descrito acima cresce com a consolidação dos direitos e com o advento do capitalismo industrial. Torna-se uma categoria de entendimento do mundo a partir da pessoa, um ente naturalmente singular e distinto, dotado de um estado psicológico, um domínio interior, no qual o conhecimento de si é a condição básica para todo o outro conhecimento. Em termos dessa noção de 'eu', constituem-se as engrenagens das socialidades modernas, nas quais funcionariam as instituições com as ideias de dever, responsabilidade, direitos, escolhas e liberdades individuais. Além disso, nessa ótica, as fronteiras da corporeidade seriam marcadas rigidamente por uma vida interior da psique, na qual as experiências se insculpem, legitimando a biografia individual.

Nikolas Rose (1998; 2001; 2011), apoiado nas ideias de Foucault, difere-se das análises anteriores e não pensa a constituição do 'eu', 
do sujeito moderno, a contar transformações sociais mais amplas, como se houvesse uma história contínua. Essas narrativas, segundo o autor, remontariam uma espécie de história sequencial, como supor que existiria uma transição do feudalismo para o capitalismo e, consequentemente, da tradição para modernidade. $\mathrm{O}$ indivíduo, assim, não pode ser entendido como efeito de uma mudança social geral. Em função disso, Rose caminha por outro lado, articulando os conceitos de 'tecnologia' e 'subjetivação', entendendo que o 'eu' não pode ser considerado como substância anterior a qualquer tipo de história ou sociação, pois são trajetórias interligadas.

Para Rose (2001), a experiência na qual os seres humanos acreditam ser constituídos como pessoas, com características de autorrealização, poderes pessoais e liberdade infinita, é resultado de um conjunto de tecnologias humanas: "[...] tecnologias que tomam modos de ser humano como seu objeto" (Rose 2001:38). Nesse caso, tecnologia refere-se a qualquer agenciamento ou conjunto estruturado para uma racionalidade prática, orientada para um alvo de forma mais ou menos consciente, em que a subjetivação tem sua própria história. Aqui, subjetivação é entendida não como sistema externo de poder ou subjugação a outro, mas como processo pelo qual somos 'fabricados' como sujeitos de certo tipo.

Dessa maneira, ele sugere estudar as técnicas de invenção do 'eu' por meio das quais os indivíduos constituem a si mesmos, isto é, como os seres humanos constroem os instrumentos à medida em que esses instrumentos os constituem historicamente, propondo uma ontologia histórica e uma genealogia das relações que os seres desenvolvem consigo. “Dispositivos de 'produção de sentido' - grades de visualização, vocabulários, normas e sistema de julgamento - não são produzidos pela experiência; eles produzem a experiência" (Rose 2001:36, grifo do autor). Quer dizer, as formas pelas quais os seres humanos atribuem sentido à sua experiência têm sua própria história.

Portanto, ao propor uma genealogia da subjetivação, Rose (2001, 2011) não se preocupa com uma continuidade do 'eu', criticando a 
pressuposição de uma história contínua, unitária e totalizadora. Ele foca nas descontinuidades, nas linhas contingenciais que desestabilizam o presente, nos exames que dão conta da multiplicidade das linguagens de pessoa que tem se desenvolvido, compreendendo que esse tipo de investigação deve ocorrer ao longo de uma série de trajetórias, num feixe de relações. A genealogia proposta toma a compreensão do que significa ser humano como o local de um problema histórico e não como a base de uma narrativa histórica. ${ }^{4}$

Nesse sentido, Rose $(2001,2011)$ parte do pressuposto de que as ciências psi (psicologia, psicanálise e psiquiatria) inventam sistemas de interpretação, administração e governo de nossas existências. A questão central que o autor investiga, a partir dos dois conceitos acima referenciados (tecnologia e subjetivação), é como as ciências psi produzem subjetivação a partir de algumas tecnologias do 'eu'. De acordo com ele, foi nas sociações ocidentais modernas que surgiu a psicologia como disciplina científica, "[...] como um conhecimento positivo do indivíduo e como uma forma particular de falar a verdade sobre os humanos e de agir sobre eles" (Rose 2001:34). Contudo, a aparição e o desenvolvimento dessa ciência são circunscritos por uma heterogeneidade de discursos, ideias e modelos acerca do "eu”, não havendo um modelo único de pessoa que ocupe lugar privilegiado nas teorias psicológicas.

"As disciplinas 'psi', em parte como consequência de sua heterogeneidade e falta de um paradigma único, adquiriram uma peculiar capacidade penetrativa em relação às práticas para a conduta da conduta. Elas têm sido não apenas capazes de fornecer toda uma variedade de modelos do eu, mas também de fornecer receitas praticáveis para a ação em relação ao governo das pessoas, exercido por diferentes profissionais, em diferentes locais. Sua potência tem sido aumentada ainda mais por sua capacidade para suplementar essas qualidades praticáveis com uma legitimidade que deriva de suas pretensões a dizer a verdade sobre os seres humanos. Elas se disseminaram rapidamente, por meio de sua pronta traduzibilidade, por programas para remoldar os mecanismos de autodireção dos indivíduos, estejam esses na clínica, na sala de aula, no consultório, 
na coluna de conselhos das revistas ou nos programas confessionais da televisão" (Rose 2001:46).

É justamente essa heterogeneidade que o autor denomina como 'generosidade das ciências psi', pensada em virtude da 'unificação' dos regimes de subjetivação em termos do 'eu' que tem a ver com um modelo singular de expertise positiva sobre o ser humano. Isto é, as ciências psi concederam aos grupos profissionais e as outras áreas do conhecimento, suas explicações e validações, vocabulários e tipos de julgamento para aplicação no interior de seus adeptos. Agora, tem-se a base para tornar os problemas da conduta humana inteligíveis e intervir sobre eles, a começar, sobretudo, dos discursos e de tecnologias especializados e a maneira como essas produzem um tipo de olhar perito.

Observa-se nas diferentes proposições teóricas que estimularam o desenvolvimento das ciências psi, a tentativa de definir o que é o 'eu', de conceituá-lo. Por causa disso, há o desenvolvimento de um conjunto de visões. Essas tentativas de descrição do 'eu' em estado puro, simbolizadas por uma diversidade de correntes de pensamento no campo das ciências psi, propiciou, de acordo com Rose (2011), técnicas de condutas de si, que, por sua vez, conceberam modelos, ora para o controle de si, ora para o autoconhecimento.

A premissa de que podemos nos erigir, sermos mais eficientes com a manipulação da dinâmica de comportamento, em alguma medida, faz com que tenhamos a capacidade de desconstruir e construir atitudes. Essa é a funcionalidade, ou melhor, a generosidade das ciências psi. Maximizar ou minimizar; construir ou desconstruir, certo é que temos a possibilidade de realizarmos a melhora de nossos comportamentos para os resultados desejáveis. As ciências psi se expandem exatamente por se posicionarem como forma de atingir a autonomia do sujeito ao oferecê-lo à possibilidade de identificar um comportamento que pode ser desprogramado e substituído pelos desejáveis para que, portanto, atinja as aspirações positivas e maximizadoras de si. 
Essas tecnologias devem ser pensadas em conformidade com os seguintes aspectos: o destaque do discurso psi, a vulgarização de sua prática e a disseminação de seu vocabulário quando comparada a outras áreas do saber; a sua associação com regimes de orientação democrática e liberal, que busca uma base empírica para o alcance de resultados, de eficiência, no qual o sujeito procura se superar e ser melhor; o discurso psi tem/procura uma verdade, uma legitimação. Essas três características produzem a relação do ser consigo mesmo. A autonomia que o sujeito espera dentro desse processo de subjetivação, é a aplicação e aperfeiçoamento da técnica de manipulação de comportamento. $\mathrm{O}$ sujeito precisa se constituir como inteligível por meio de suas escolhas e as ciências psi tornam-se o caminho para tal. Esse processo associa-se a um paradigma constitutivo da própria subjetividade.

A constituição da pessoa no ocidente moderno adquire uma condição de naturalidade, na qual os indivíduos seriam lugar determinado de crenças, sentimentos e desejos, com certas capacidades inatas que os fazem capazes de decidir e agir. Nesses contextos, os seres humanos se compreendem como sujeitos psicológicos, capazes de estabelecerem relações consigo mesmos. Com essa vida psicológica interior, os indivíduos se narram e se interrogam. São empresas de si próprios, procurando uma autorrealização a partir de seu equipamento sagrado: a psique. Essa psicologização das socialidades ocidentais auxilia na compreensão das condições presentes de formulação de sujeitos, uma vez que, de acordo com Rose (2011), as ciências psicológicas tornaram-se parte da máquina de governança, ao fornecer tecnologias de individualização que dão aos sujeitos a capacidade de influenciar seus próprios corpos, pensamentos e comportamentos.

"O que as ciências psicológicas fizeram para o século XX, como sabemos, foi fornecer linguagens para compreender a nós mesmos; fornecer a base de certos tipos de competências para gerenciamento de nossos selves; proporcionar uma diversidade de maneiras de tornar problemas sócio-políticos inteligíveis e tornar possíveis programas para intervir neles; fornecer uma linguagem por meio da qual pode- 
mos nos imaginar e tornar nossas dificuldades inteligíveis [...]. Então a psicologia se tornou parte da máquina de governança, no sentido mais amplo de governança" (Rose 2010:312, grifo do autor).

Como demonstrado, com a formação das socialidades modernas e a constituição de novas formas de governo o sujeito passou a moldar-se por tecnologias de subjetivação. Nessa direção, as disciplinas psi têm desempenhado uma função importante no regime contemporâneo de subjetivação e em sua unificação sob o signo do 'eu' (Rose 2001, 2011).

Rose (2010) se pergunta se as neurociências farão, para o século $\mathrm{XXI}$, o que as ciências psicológicas fizeram para o século XX - sem que necessariamente uma anule a outra, levando em conta que os argumentos das neurociências, bem como seu vocabulário, estão sendo absorvidos por uma diversidade de áreas. Nesse sentido, se antes as tecnologias deveriam ser pensadas em relação - mas não apenas - ao destaque do discurso psi, a vulgarização de sua prática e a difusão de suas linguagens, como também sua associação com o liberalismo, agora, verificam-se maneiras neurobiológicas de pensar o 'eu' e empenhos para adotar o prefixo 'neuro' (neuroeconomia, neuroemocional, neuromercado, trabalho neurosocial, neuropsiquiatria), principalmente no tratamento de determinados distúrbios de saúde mental, que descrevem o panorama patológico dos sujeitos no neoliberalismo.

\section{O senso comum ocidental e o amor romântico}

Com os argumentos elencados nos tópicos anteriores, percebe-se que, a partir das ciências psi, a noção de sujeito leva em conta seus antecessores: consciência, personalidade e indivíduo. Isso acontece, pois, com a noção de personalidade consolidada, atrelada à ideia de consciência, procurou-se o entendimento do 'eu' interior, o que o determina, o que o diferencia - e por quais razões - de outros 'eus'. Já da noção de indivíduo à noção de sujeito, há o movimento de se perguntar o que singulariza os seres humanos. Assim, inserem-se demarcações para apartá-los uns dos outros, isolá-los do mundo social e, 
consequentemente, legitimar uma figura de um sujeito interiorizado, solitário e irredutível. Um 'eu' pensante, no qual a saúde e o seu adoecimento pertencem e se encerram especialmente nele próprio (Arendt, Quadros \& Moraes 2019).

Esse sujeito, enquanto fruto da modernidade, é entendido como universal..$^{5}$ Nesse sentido, ao falar de emoções, em particular do 'amor', e da maneira pela qual as assimilamos em nosso contexto, deve-se levar em conta a noção de pessoa fincada no mundo euroamericano: o indivíduo. Isso porque tratar das emoções perpassa, direta ou indiretamente, a discussão acerca do conceito de pessoa, que é produzido, como vimos, culturalmente.

De acordo com Catherine Lutz (1986) e Lutz \& White (1986), há um senso comum ocidental acerca das emoções, no qual elas são tratadas como mero estado subjetivo e como realidade psicobiológica, cedidas a priori e universalmente válidas - em que todo e qualquer ser humano, independente de seu contexto, teria a possibilidade de desenvolvê-las, expressando uma ideia de unidade psíquica da experiência emocional humana. Essa perspectiva, sustentada e enraizada por parte das ciências psi do século XX, fez com que as emoções fossem tratadas como uma espécie de 'dom natural' e como profundamente individuais, desagregadas dos domínios social e cultural. Dessa forma, as emoções brotariam do interior do indivíduo.

Esse senso comum ocidental pode ser mais bem compreendido com base no conceito de etnopsicologia, descrito por Lutz (1986) e Lutz \& White (1986) como conjunto de ideias compartilhadas por grupos humanos acerca das emoções. Na etnopsicologia euroamericana, as emoções se relacionariam com o primitivo, sendo pensadas enquanto parte integrante de uma irracionalidade. $\mathrm{O}$ ocidente produz uma forma de pensar na qual a emoção é o avesso da razão. Assim, a mente é sinônimo de razão, enquanto o corpo é semelhante à emoção, a emoção está identificada com um sentimento físico, sendo condicionada, por exemplo, por hormônios e outras metáforas corporais, vista como algo natural e mecânico e não cultural. 
Nessa distinção entre emoção e razão, a segunda é produzida como uma ideia "[...] intimamente relacionada à inteligência, que no pensamento euroamericano é definida como a capacidade de resolver problemas, particularmente aqueles cujos parâmetros atribuídos são técnicos, e não sociais ou morais" (Lutz 1986:289, tradução nossa). Por outro lado, a emoção está representada pelo pensamento euroamericano como irracionalidade, no qual em vários sentidos ela é entendida como um impedimento à razão, uma categoria residual que se desvia do padrão racional.

Essa forma psicologizante de representar as emoções, conforme a autora, é social e predominantemente aceita nas socialidades ocidentais. A psicologia entendeu, durante muito tempo, a emoção como essência humana, o que produziu uma formulação psicológica e não social das emoções. "Embora processos sociais, históricos e interpessoais sejam vistos como correlacionados com esses eventos psíquicos, o pensamento e a emoção são considerados propriedade dos indivíduos” (Lutz 1986:289, tradução nossa). Ou seja, pensamento e emoção são vistos como realidades mais autênticas e mais verdadeiras do 'eu' em comparação com a relativa falta de autenticidade da fala e outras formas de interação.

Outra maneira de representar as emoções no pensamento euroamericano é tratá-las como se fossem parte da subjetividade do indivíduo, em que somente ele teria ou sentiria certas emoções, sendo reduzidas a opiniões e valores particulares. Nessa perspectiva, as emoções são do 'eu' de uma maneira que os pensamentos não são, em razão de os pensamentos serem objetivos, enquanto os sentimentos são subjetivos, não são completamente comunicáveis e são exclusivamente do sujeito. Desse modo, as emoções representam privacidade ou inviolabilidade individual. Entende-se que elas não podem ser verdadeiras ou absolutamente conhecidas, exceto por meio da autorrevelação, isto é, através de uma decisão por parte do indivíduo que experimenta a emoção de comunicá-la. Assim, não é possível determinar conclusivamente o que outra pessoa está sentindo apenas com base na observação (Lutz 1986; Lutz \& White 1986). 
Lutz (1986) chega à conclusão de que essas formas com que as emoções são representadas na cultura euroamericana são formas ideológicas que revelam relações de poder, mormente as de gênero. À vista disso, ela propõe que as emoções devam ser entendidas como formações culturais e morais que são atravessadas por relações de poder e pertencimento, construtos que dependem diretamente da cultura para se expressar. Nessa lógica, devemos começar por aquilo que as ciências psi negaram: avaliar o conjunto de relacionamentos sociais e os significados existenciais que as socialidades apresentam para pensar a emoção. Em suma, para Lutz (1986) e Lutz \& White (1986) a visão da emoção que dá primazia às experiências corporais internas influencia e são influenciadas pela maioria das teorias psicológicas, baseadas em uma concepção altamente individualizada de pessoa.

A perspectiva dumontiana apresentada anteriormente para falar do individualismo como valor do ocidente, como ideologia, foi utilizada por Ricardo Benzaquen de Araújo e Eduardo Viveiros de Castro (1977) para analisarem a tragédia shakespeariana Romeu e Julieta como mito de origem do amor moderno. ${ }^{6}$ A noção de amor que emerge a partir da obra sustenta a ideia desse sentimento como algo mágico, que brota do interior do sujeito, oriundo de sua intimidade, que ilustra os argumentos de Lutz (1986) e Lutz \& White (1986) no que se refere às emoções serem absorvidas por uma ideologia individualista presente na etnopsicologia euroamericana. Assim, o debate trazido pelos autores indica uma visão do amor como sentimento construído culturalmente e localizado historicamente.

Dumont (1985) afirma que o indivíduo que (re)aparece no Renascimento pode ser tratado como a gênese mais próxima daquilo que somos. Baseados nisso, Benzaquen Araújo \& Viveiros de Castro (1977) propõem uma reflexão sobre a ideia do amor romântico, ilustrado dentro da trama de Romeu e Julieta. Nela, identifica-se uma correlação entre a ideologia individualista e o surgimento do amor ocidental moderno, na qual os autores respondem quais são as consequências 
da produção do indivíduo enquanto valor, ligada à ideia de direitos e deveres no mundo público.

A narrativa básica da obra em questão é a de dois enamorados que se amam, mas não podem ficar juntos devido à inimizade e ao ódio que separam suas famílias. Por conta disso, procuram sobrepor seus interesses individuais ao desejo de seus familiares. Nessa tragédia, o amor é colocado acima de qualquer outro elemento, um sentimento sobrenatural e arrebatador que se opõe a quaisquer valores presentes no mundo social que tentem interrompê-lo. $O$ fato de saberem que pertencem a famílias rivais não os inibem, ao contrário, o casal não cogita uma desistência do amor.

Nesse movimento, os jovens procuram não mais se definir como Montechio e Capuleto, sobrenomes de suas famílias, mas por sua singularidade, na qual a família não pode intervir. A briga do casal é para se desfazer de uma ordem social que determina o seu 'lugar', o amor seria o elemento para ignorar diretamente a diferença social entre Romeu e Julieta. Dessa forma, eles descartam suas identidades atreladas ao nome/nascença e, segundo Benzaquen Araújo \& Viveiros de Castro (1977), inauguram uma espécie de individualismo moral, na qual as identidades não importam mais, sendo menosprezadas. Isso é fundamental para o desenvolvimento da ideia de intimidade, que constituirá o indivíduo moderno e o defenderá da ideia de determinação por meio de papéis socialmente estabelecidos, a exemplo do sobrenome.

Nessa ótica, individual e social se refutam. O amor é corpo, sinônimo de coração que caracteriza o 'eu' individual. Em contrapartida, temos o 'eu' social e suas forças, como a família. O amor passa a ser entendido não como algo externo, mas uma instância interna que coage o indivíduo a 'bater de frente' com a ordem social. De acordo com os autores, isso só faz sentido se captarmos que a tragédia shakespeariana apresenta as contradições do momento de transição entre duas ordens sócio-históricas: holista, tradicional, herança do medievo; para individualista, na qual o indivíduo é colocado no centro do universo, ideal introduzido com a Renascença. 
Holismo pode ser compreendido como a valorização do todo sobre as partes, em que as dimensões do meio social se expressam no indivíduo, certificando seu pertencimento e um lugar. São universos nos quais os valores dos grupos são superiores aos interesses privados e pessoais. Numa 'sociedade holista', as pessoas estão ligadas por algo externo a elas e se esquecem de si próprias e os valores repousam na sociedade como um todo. Já num universo simbólico individualista, o indivíduo é o valor central, é o fim último, um bem supremo e a totalidade deve ser modificada para se adequar aos anseios individuais.

Benzaquen Araújo e Viveiros de Castro (1977) declaram que, no ocidente moderno, verifica-se a ascenção do individualismo e a consolidação dessa ideologia como orientação das práticas sociais, já o holismo pode ser observado em outras organizações sociais, como o caso da Índia, e em comunidades tribais. Em 'Romeu e Julieta', notase uma ideia de 'eu' individual que é ilustrado pelo amor em oposição ao 'eu' social, representado pela família. O que estrutura a tragédia é a dicotomia entre posição social e dimensão individual do sujeito. A ideia de mito de origem do amor moderno presente é demarcada por essas duas gramáticas. Na verdade, o conflito entre essas duas ordens cria a própria narrativa.

O amor, germinado no íntimo de Romeu e Julieta, faz com que eles contestem enfaticamente o social, priorizando suas vontades. É uma força cósmica incontrolável que abastece o sentido deles a ponto de reunirem forças para enfrentar qualquer obstáculo. Se o destino quis assim, não há justificativas para contrariá-lo, pois eles foram destinados a amar um ao outro para sempre. Marcados por essa potência interior, não há nada externo que os impeça de amar. Essa concepção, que perpassa toda a trama, desenvolve-se em assimetria a qualquer instância de ordem social que tente frear o sentimento (Araújo \& Castro 1977).

Como demonstrado, a divergência entre afeto e obrigações sociais perpassa o centro da trama de 'Romeu e Julieta', na qual as relações sociais são feitas de obrigações radicalmente opostas ao amor sentido 
por eles. Essa forma de pensar individualista revela que as características psicológicas específicas dos indivíduos passam a ser extremamente valorizadas. Contudo, temos também a noção de utilização do amor como benefício à ordem social. Quer dizer, por meio do amor, os jovens namorados acreditam poder tudo, inclusive superar a discórdia e os conflitos entre as suas famílias rivais, estabelecendo pactos harmônicos entre elas. $\mathrm{O}$ amor incontrolável seria motivo também para integração social.

Esses aspectos mostram que, nessa perspectiva, o amor é um sentimento que vem do acaso, espontâneo e que traça destinos, impõe e contraria as obrigações familiares e sociais, submetendo os indivíduos a valores de outra ordem. Há aí uma ideia de amor idealizado, de mútua adoração, reciprocidade, docilidade e ternura, o que o torna uma instância transcendental. Benzaquen Araújo \& Viveiros de Castro denominam esse fenômeno como 'desrazão amorosa' (1977:164), que leva os indivíduos a se afastarem de uma razão social tradicional e holística. Agora, a metáfora do coração associada ao amor se coloca acima dos laços de sangue, a escolha do parceiro exclui qualquer necessidade externa.

Rezende \& Coelho (2010) comentam que temos que tratar 'Romeu e Julieta' para além de um mito de origem do amor moderno como propõem os autores citados. Isso porque essa tragédia desenvolve certos aspectos que a transcendem, formulando percepções bem singulares acerca do amor presentes no imaginário social até hoje. Não à toa, algumas das ideias presentes na trama são comuns em várias produções discursivas contemporâneas, como músicas e filmes, no universo da comunicação de massas.

Esse amor romântico incorpora o casamento monogâmico, que passa a ser visto como garantia de moralidade, uma instituição na qual um homem e uma mulher decidem por consentimento mútuo o que é novo historicamente - fundar uma família baseada na razão do amor e não na paixão sexual. Aqui, amor e desejo se distinguem. Quem ama, portanto, não sentiria atração e desejo por mais ninguém. 
Verifica-se também uma narrativa de casal igualitário, que, apesar de se entenderem como indivíduos, quando enamorados, assumem uma identidade homogênea, na qual se perde a individualidade, o que Tânia Salem (1989) chama de 'simbiose do casal apaixonado'. Essa simbiose acontece, segundo a autora, quando o casal se entende como indivíduo dual, isto é, um como parte integrante do outro. Ou seja, não existe mais Romeu sem Julieta e Julieta sem Romeu. Eles só são reconhecidos juntos, agora os corpos estão ligados e tornaram-se um só: alma gêmea.

Por essa razão, seria mais coerente interpretar a tragédia, sobretudo ao considerar o conceito de mito, como uma 'matriz' cultural que dissemina a ideia de amor impossível, que arrebata, algo mágico e sobrenatural. Como consequência dessa matriz, temos a propagação de temas fincados na ideia de amor romântico, que atuam em prol desse imaginário.

\section{Amor romântico: uma experiência culturalmente localizada?}

Desde a primeira vez que foi encenado, no século XVI, observa-se que 'Romeu e Julieta' tem servido como base e referência para representação imagética de inúmeros casais, ${ }^{7}$ sobretudo aqueles que amam e querem afirmar o seu direito sobre esse sentimento, independente dos pesos e das forças contrários. Esse 'mito de origem do amor romântico’ deve ser pensado à luz da moderna noção de indivíduo, na qual se tem a submissão do ser pela incontrolável força do amor e suas determinações.

Na verdade, essa narrativa só tem sentido no universo de valores individualistas. ${ }^{8} \mathrm{O}$ trabalho de Luhmann (1991) mostra tal movimento ao compreender uma convergência entre as ideias de amor construídas na Europa nos últimos séculos e a transformação nas relações íntimas - entendidas por ele como interpenetração inter-humana - em essencial o grau de individualização. Esse exercício é realizado considerando aspectos macroestruturais, como a adaptação entre capitalismo, individualismo e conjugalidade, imprescindíveis para a 
concepção de amor romântico e consagração do ideal de família monogâmica. O amor romântico serve, então, como parâmetro das relações amorosas que visam a materializar-se na esfera da conjugalidade: "torna-se o fundamento do casamento, esse se torna mérito sempre renovador do amor" (Luhmann 1991:187).

Para Luhmann (1991), o amor romântico pode ser compreendido, em resumo, como uma suposta atração acentuada que circunscreve o enaltecimento do outro numa dimensão erótica, formulando uma expectativa mutuamente consentida de permanência com parceiro por um tempo indeterminado, de preferência, se infindável. Nessa perspectiva, "se espera que o sujeito fique sempre a mercê de uma paixão, contra a qual nada se pode fazer antes de mergulhar numa relação amorosa profunda" (Luhmann 1991:71).

Como aponta Macfarlane (1990), é a partir do Renascimento e, em seguida, com a consolidação do ideal da burguesia e a instalação de sua agenda na administração do Estado, que se torna visível a cimentação do princípio que sustenta o amor romântico: o elo entre namoro/casamento por amor. $\mathrm{O}$ casamento deixou de ser apenas um ato político ou comercial e o amor começou a fazer parte dos contratos matrimoniais. Antes, o casamento era arranjado para se manter os bens na família, a riqueza dos nobres entre si. Contudo, as premissas individualistas formam o sustentáculo desse amor: 'até que a morte nos separe', no qual o poder do clero e da aristocracia, bem como suas influências, passam a ser secundários.

Para ilustrar esse aspecto, Rezende \& Coelho (2010) ressaltam que os sentimentos, em geral, devem ser compreendidos como tributários das relações sociais e do contexto cultural em que emergem, de acordo com o que o ciúme - considerado como importante estado emocional no ocidente - está intrinsecamente associado à monogamia do modelo judaico-cristão, só fazendo sentido à luz do parentesco ocidental e da maneira com a qual se concebem os relacionamentos amorosos nessa região, que são assentados no mito do amor romântico. 
As autoras indagam o ciúme, o qual, segundo elas, não pode ser considerado como natural, muito menos como resultado espontâneo de exigências de exclusividade sobre aqueles a quem amamos. Ao contrário, seu desenvolvimento se dá em torno de "regras de relacionamento" socialmente compartilhadas, que o tornam legítimo e esperado em relações conduzidas "[...] por expectativas prescritas de reciprocidade e exclusividade, mas que o condenam em outros modelos de relacionamento nos quais a 'regra' é o compartilhar do outro, a exemplo dos modelos poligâmicos" (Rezende \& Coelho 2010:12).

Com isso, Rezende \& Coelho (2010) demonstram que amor e ciúme formam um complexo de aparência indissociável para as subjetividades ocidentais. Essa maneira moderna de amar, ao atrelar o sentimento amoroso ao casamento monogâmico, autoriza uma imposição ao parceiro de exigência de reciprocidade e exclusividade. Legitimado, o ciúme pode ser considerado como 'prova de amor' e sua ausência seria sinal de desinteresse amoroso. Portanto, a construção do ciúme é social e resulta de diferentes padrões de reação, mas há alguns traços comuns no contexto ocidental que são pautados por uma ideia de envolvimento real ou imaginário do parceiro com outra pessoa fora de seu relacionamento primário. Um sujeito é tido pelo ciumento como valioso e importante, o centro de sua vida, numa relação na qual ele procura se inserir como dependente em termos emocionais. Nessa lógica, o ciúme parte de um rival real ou imaginário, incita uma reação frente à ameaça e, por fim, faz o ciumento arrumar meios para eliminar os riscos da perda de seu amor para outrem.

Todos esses autores reconhecem que existem diferenças culturais na expressão e vivenciamento do sentimento amoroso que não podem ser ignoradas, pois, a depender do universo simbólico, temos a valorização de certos temas e tópicos, em que uns são enaltecidos e outros suplantados. Dennis Rougemont (1988) argumenta que, no ocidente, há uma exaltação do amor como fundamento para o casamento, porém essa premissa, na China, por exemplo, não tem cabimento e soaria como ofensivo aos enamorados. Nesse contexto, de 
acordo com o autor, a paixão amorosa é vista como doentia, sendo depreciada pela moralidade corrente.

Nessa direção, Anthony Giddens (1993) fala de um ethos do amor romântico presente nas gramaticas sociais ocidentais, entendendo-o como a capacidade de firmar um vínculo emocional durável com outro, que tem como suporte os atributos intrínsecos do próprio vínculo. Giddens ressalta a importância de diferenciar o 'amor romântico' do 'amor apaixonado'. Enquanto o primeiro seria um fenômeno culturalmente mais específico e localizado, o segundo seria um fato relativamente universal (Giddens 1993).

Em diálogo com alguns desses aspectos, Josefina Pimenta Lobato $(1997,2012)$ enxerga uma ambiguidade na definição do que seja considerado amor. Ao reconhecer isso, a autora defende que não é possível reduzi-lo a um acontecimento peculiar do ocidente. $\mathrm{O}$ amor, afirma, pode ser sim visto em contextos não ocidentais.

"Caso se o defina apenas como a capacidade de se apaixonar, de ter sentimentos de ternura, [...] de sofrer pelo amor não correspondido, não há como reduzi-lo a um acontecimento peculiar apenas ao ocidente, assim como não se pode limitar a uma cultura específica a capacidade de sentir raiva, medo ou inveja" (Lobato 2012:21).

Então, o que distinguiria o amor no ocidente? De acordo com a autora, uma prescrição ideológica de que se apaixonar é o alicerce extremamente apetecível para o namoro e o casamento. Daí, a sua restrição ao ocidente torna-se mais coerente. Em torno disso, ela propõe a diferenciação entre 'paixão amorosa', visualizado em outros contextos culturais e 'amor romântico', circunscrito à experiência ocidental. Para entender esse ponto, é preciso realizar uma pequena digressão.

Lobato $(1997,2012)$ defende que há semelhanças da expressão do sentimento amoroso no contexto de sociações ocidentais e não ocidentais, apesar de considerar diferenças notáveis associadas às condições de manifestação desse sentimento. Para explicar essa afirmação, ela recupera também as concepções dumontiana de individualismo e holismo. Em torno disso, propõe as categorias de 'amor domesticado' 
e 'amor disciplinado' para defender a tese de que a 'paixão amorosa' pode ser observada em outros contextos culturais, porém a orientação entre individualismo e holismo distinguirá sua exteriorização.

Tanto o 'amor domesticado', quanto o 'amor disciplinado' procuram, de formas diferentes, tratar do caráter antilógico e fortuito da paixão amorosa, entendida a partir da metáfora 'selvageria'. 'O amor domesticado’ é presente em socialidades com orientação individualista, em que a 'selvageria' do amor passional é celebrada e interpretada como imperativo para felicidade, glorificação, aperfeiçoamento de si e autorrealização, mesmo que para isso "[...] seja preciso confrontar as constrições impostas pela moral e pelas lealdades políticos-familiares" (Lobato 2012:21).

Já nas 'sociedades holistas', temos o 'amor disciplinado', em que a 'selvageria' da paixão não é tolerada, precisando ser controlada para respeitar a ordem social presente e fazer com que suas engrenagens continuem funcionando. As responsabilidades dos papéis sociais são mais fundamentais que o sentimento pessoal e, a paixão aqui pode desmoralizar, mesmo que indiretamente, outros agentes que estão sob domínio das normas socialmente compartilhadas. Nessas circunstâncias, a paixão é vista como doença que induz à desobediência dos parceiros e, por consequência, podem desajustar princípios nos quais o grupo social de que fazem parte se ancora.

É aí que, segundo a autora, pode-se efetivamente identificar a diferença entre ocidentais e não ocidentais no que se refere ao amor. Nos primeiros, observa-se que o indivíduo está à frente de todos os outros valores, por esse motivo o amor lhe serve como fundamento para o namoro e o casamento, uma vez que respeita suas vontades e o próprio amor é tido como uma condição incontrolável e arrebatadora. Em contraste, nas socialidades não ocidentais - a autora utiliza como exemplos China, Taiwan, Índia e Arábia Saudita, o amor não é justificativa para iniciar ou terminar uma relação amorosa, nem mesmo para confrontar instituições sociais como a família. Casamento ou namoro baseado no amor é visto como interesseiro e egoísta, pois 
se ergue em detrimento de valores familiares e aspectos econômicos. Essa caracterização é oposta do que ocorre no mundo euroamericano, já que, nesse contexto, o que é tido como interesseiro é "[...] justamente aqueles casamentos que levam em conta motivações não concernentes exclusivamente ao amor" (Lobato 2012:24).

Nesse modus operandi, quando alguém casa ou namora por interesse, não se pode admitir. A autora entende que existe uma espécie de 'coerção para amar', o que, no ocidente, é tão forte e evidente que, nas narrativas de relações adúlteras, observa-se que os amantes não se enlaçam por fatores econômicos nem por obrigações morais, mas pela paixão ardente que os tocam. Inclusive, "o amor pelo amor pode induzir os enamorados a manter a representação do papel de apaixonados apesar desse sentimento não mais existir" (Lobato 2012:24). Essa seria uma das consequências possíveis da pressão cultural para amar.

Como discutido, em outros contextos culturais, o 'amor' não tem importância, sequer é falado. A 'presença' dele não é um determinante ou entrave para o estabelecimento de um relacionamento. Isso não significa que não exista a ideia de uma 'paixão amorosa', apenas que é tratada como secundária, pois se prioriza não a relação entre o marido e a mulher e seus interesses e prazeres pessoais, mas os deveres e responsabilidades sociais com a comunidade na qual estão inseridos (Lobato 1992, 2012).

Com esse esforço teórico, notabiliza-se que a 'paixão amorosa' é um sentimento manifestado quer nas 'sociedades holistas', nas quais o valor é o grupo e, consequentemente, o 'amor disciplinado', quer nas 'individualistas', onde predomina o 'amor domesticado'. Ou seja, a 'paixão amorosa' se aplica em diversos contextos socioculturais. Portanto, admite-se a existência dessas em outras socialidades, nas quais ela é direcionada de modo diverso.

A tese de Lobato $(1992 ; 2012)$ assume também outro compromisso: fugir das premissas ora particularistas, ora universalistas sobre o amor. Quer dizer, segundo a autora, no debate antropológico sobre o amor, há, com a primeira corrente, uma noção de que o amor seria 
peculiaridade da Europa e, portanto, um sentimento raro em outros contextos. Já na segunda perspectiva, sustenta-se o argumento de que o amor estaria presente em todos os povos e regiões, desassociando-o do casamento, que é intrínseco à cultura euroamericana.

Dessa forma, Lobato $(1992,2012)$ ultrapassa as duas posições descritas anteriormente: uma que entende que a paixão amorosa é exclusiva e excepcionalmente inserida no mundo ocidental, concepção que visualiza "[...] um vazio onde há experiências amorosas incontestáveis [...]" (2012:31); outra que enxerga a mesma noção de amor em toda parte, sem considerar a diferentes gramáticas culturais.

\section{Considerações finais}

Como vimos, os argumentos de Lobato $(1992,2012)$ se contrapõem e desmistificam algumas idealizações, como se o amor, por exemplo, fosse algo mágico de outra ordem e sobrenatural. Queremos ressaltar que nossos sentimentos são construções culturais com reflexos sociais e políticos, não são naturais ou espontâneos.

Por esse motivo, propusemos, no decorrer deste texto, que a noção de 'amor' seja pensada em virtude da noção de 'pessoa', pois ambas fazem parte de um mesmo universo simbólico. Como demonstramos, ao longo da história, a própria maneira de se entender o que é uma pessoa se transforma. No ocidente, ocorreu uma metamorfose específica dessa noção trazendo à tona a ideia de indivíduo, visto como pessoa limitada a um contexto sociocultural. Queremos destacar que este trabalho não abordou a noção de pessoa como fundamento para o amor moderno como uma associação determinista ou numa premissa de causa e efeito, como se um fosse, necessariamente, condicionante para o outro.

Nessa lógica, a nossa argumentação segue alguns pressupostos levantados por Lobato $(1997,2012)$. Em sua visão, também temos o desenvolvimento da 'paixão amorosa' em outros contextos além do ocidente, inclusive dando indícios de que os europeus possam ter se apropriado dessa noção em contato com outros povos. Porém, em 
outras conjunturas, não há a vinculação entre amor e casamento. Esse seria, na realidade, o principal atributo distintivo dos ocidentais devido às premissas individualistas. Por essa razão, no ocidente, temos o desenvolvimento de um 'amor domesticado' e, fora dele, um 'amor disciplinado'.

Em síntese, ainda que o amor possa ser encontrado em todos os lugares, não se ama ou se expressa esse sentimento da mesma forma e, principalmente, não se dá a ele o mesmo lugar na constituição dos vínculos sociais. Esses questionamentos destacam a particularidade histórica e cultural da estreita associação que o ocidente moderno realizou entre amor e casamento. $\mathrm{O}$ que se manifesta na cultura ocidental posterior à Idade Média é o amor como algo natural e prelúdio ao casamento, que só pode ser entendido se levarmos em consideração o ideal individualista e seu processo de transição e consolidação. Nessa circunstância, o amor que começa a ser domesticado é indispensável para a conjugalidade, favorecendo a concepção de satisfação individual atrelada aos enamorados que se atraem socialmente, fisicamente e mentalmente em termos de 'fisionomia' e 'caráter'.

\section{Notas:}

1 Ver: https://brasil.elpais.com/ideas/2020-03-22/o-coronavirus-de-hoe-e-o-mundo-de-amanha-segundo-o-filosofo-byung-chul-han.html. Acesso em 0/03/2020.

2 Strathern disserta sobre esses aspectos no contexto dos anos 80 , em que havia a crise de representação na antropologia. Ela propõe pensarmos as categorias antropológicas e o próprio texto etnográfico como ficções persuasivas (2013).

3 Georg Simmel (2006), já no século XIX, contestava o conceito de 'sociedade', inaugurando o problema da representação e dos limites das ciências humanas em um caminho totalmente inverso ao seu contexto. Ao dar preferência ao termo 'sociação' à 'sociedade', ele afirmava que não havia sociedade absoluta como condição prévia para que surjam diversos fenômenos de união, "[...] pois não há interação absoluta, mas somente diversas modalidades dela, cuja emergência determina a existência da sociedade, da qual não são nem causa nem efeito, mas ela própria de maneira imediata. Somente a extraordinária pluralidade e variedade destas formas de interação a cada momento emprestam uma aparente realidade histórica autônoma ao conceito geral de sociedade" (Simmel 2006:65). Por esse ângulo, enquanto o ter- 
mo 'sociação' procura enfatizar o elemento processual do social, a ideia de sociedade nos fornece a noção de algo pronto e estático.

4 Rose $(1998,2001,2011)$ propõe, em suas obras, tratar a noção de 'eu' numa perspectiva mais processual e relacional, na qual o 'eu' não seja determinado pela sociedade e suas transformações. Por essa visão, o ser humano não pode ser entendido como uma entidade histórica, mas sim alvo de descontinuidades, as quais podem ser avaliadas na multiplicidade de estratégias e táticas de subjetivação, em que se desenvolvem diversas práticas, em diferentes contextos e em relação a diferentes classificações de pessoa.

5 A noção de pessoa nas sociedades ocidentais modernas, bem como aquilo que a constitui, não pode ser utilizada como parâmetro para pensar outros contextos culturais. Interrogar a 'modernidade' faz-se necessário para não cometer esse equívoco. Essa, por sua vez, é fruto do que Bernardino-Costa \& Grosfoguel entendem como "[...] sistema-mundo capitalista/patriarcal/cristão/moderno/colonial europeu [...]" (2016:17), que surge a partir de 1492. Trata-se, por fim, de um amplo paradigma que semeia as ideias de individualismo, progresso e confiança na razão consolidado com a finalidade de gerir, controlar e conquistar povos não europeus.

6 Ao utilizarem a concepção de mito levistraussiana, os autores o entendem como uma narrativa coletiva que produz certos debates de elementos considerados fundamentais para uma determinada sociedade, em que os agentes sociais se enxergam. Atesta-se que 'Romeu e Julieta' representa simbolicamente a maneira pela qual se vivencia o amor no mundo euroamericano. Isto é, a própria coletividade se reconhece na narrativa, sendo o mito uma produção coletiva.

7 O conceito de 'representação imagética' é abordado aqui a partir das visões de Aumont (1993), que o entende como "[...] um processo pelo qual se institui um representante que, em certo contexto limitado, tomará o lugar do que representa” (Aumont 1993:103). A título de exemplo, a novela e seus elementos imagéticos apresentados em certo contexto são os sentidos. Sendo assim, estão no lugar do que representam.

8 De acordo com Dumont (1993), a valorização do individualismo se deu no passar de vários séculos. Com o calvinismo, esse processo chega a seu estágio final. $\mathrm{O}$ indivíduo está agora 'no mundo', onde o valor individualista impera sem restrições.

\section{Referências:}

ARENDT, R., QUADROS, L. \& MORAES, M. 2019. "Digressões acerca da noção de estilo: contribuições para uma perspectiva não moderna do eu”. Psicologia Eु Sociedade, 31(1):01-16.

ARAÚJO, R. \& CASTRO, E. 1977. Romeu e Julieta e a Origem do Estado. Rio de Janeiro: Zahar.

AUMONT, Jacques. 1993. A Imagem. Campinas: Papirus. 
BERNARDINO-COSTA, J. \& GROSFOGUEL, R. 2016. "Decolonialidade e perspectiva negra”. Sociedade e Estado, 31(1):15-24.

DELEUZE, Gilles. 1974. Lógica do sentido. São Paulo: Perspectiva.

DUMONT, Louis. 1993. O individualismo: uma perspectiva antropológica da ideologia moderna. Rio de Janeiro: Rocco.

FOUCAULT, Michel. 2000. Doença mental e psicologia. Rio de Janeiro: Tempo Brasileiro.

GEERTZ, Clifford. 1997. O saber local: novos ensaios em antropologia interpretativa. Petrópolis: Vozes.

GIDDENS, Anthony. 1993. A transformação da intimidade: sexualidade, amor $\mathcal{E}$ erotismo nas sociedades modernas. São Paulo: UNESP.

HAN, Byung-Chul. 2020. O Coronavírus de hoje e o mundo de amanhã, segundo o filósofo Byung-Chul Han. (https://brasil.elpais.com/ideas/2020-03-22/ocoronavirus-de-hoje-e-o-mundo-de-amanha-segundo-o-filosofo-byung-chul-han. html; acesso em 30/03/2020).

LÁZARO, André. 1996. Amor: do mito ao mercado. Petrópolis: Vozes.

LOBATO, Josefina. 1997. Amor, desejo e escolha. Rio de Janeiro: Record/ Rosa dos Tempos.

2012. Antropologia do Amor: do Oriente ao Ocidente. Belo Horizonte: Autêntica.

LUHMANN, Niklas. 1991. O amor como paixão: para a codificação da intimidade. Rio de Janeiro: Bertrand Brasil.

LUTZ, Catherine. 1986. "Emotion, thought, and estrangement: emotion as a cultural category". Cultural anthropology, 1(3):287-309.

LUTZ, C. \& WHITE, G. 1986. "The anthropology of emotions”. Annual Review of Anthropology, 15(1):405-436.

MACFARLANE, Alan. 1990. História do casamento e do amor: Inglaterra, 13001840. São Paulo: Companhia das Letras.

MAUSS, Marcel. 2003. Uma categoria do espirito humano: a noção de pessoa, a de 'eu'. São Paulo: Cosac Naify.

REZENDE, C. \& COELHO, M. 2010. Antropologia das emoções. Rio de Janeiro: FGV Ed.

ROSE, Nikolas. 2001. "Como se deve fazer a história do eu?" Educação $\mathfrak{E}$ Realidade, 26(1):33-57.

1998. Governando a alma: a formação do eu privado. Petrópolis: Vozes.

2010. "Cérebro, self e sociedade: uma conversa com Nikolas Rose".

[Entrevistadora]: SPINK, Mary Jane. Physis-Revista de Saúde Coletiva, 20(1):301324. Vozes.

2011. Inventando nossos selfs: psicologia, poder e subjetividade. Petrópolis, RJ:

ROUGEMONT, Dennis de. 1988. O amor e o ocidente. Rio de Janeiro: Guanabara. 
SALEM, Tania. 1989. "O casal igualitário: princípios e impasses”. Revista Brasileira de Ciências Sociais, 3(9):24-37.

SIMMEL, George. 2006. Questões fundamentais da sociologia. Rio de Janeiro: Zahar.

STRATHERN, Marylin. 2013. Fora de contexto: as ficções persuasivas da antropologia. São Paulo: Terceiro Nome. 2014. O efeito etnográfico e outros ensaios. São Paulo: Cosac Naify.

VAINFAS, Ronaldo. 1992. Casamento, amor e desejo no ocidente cristão. São Paulo: Ática.

The Western Notion of Personhood as Fundament of Romantic Love

\begin{abstract}
Starting from the idea that emotional experiences are linked to social dynamics and cultural meanings, the purpose of this article is to question the notion of the Western person and his assumption of universality with regard to emotions, especially love. In this sense, we asked whether other people's notions produce different conceptions about this feeling. With this, we denaturalize the concept of the person that is familiar in Western societies and, at the same time, we show how this category was decisive for the notion of romantic love, still present in Western common sense, being illustrated by films, novels, songs and drawings.
\end{abstract}

Keywords: Love, Emotions, Individual, Person.

Recebido em maio de 2021. Aprovado em novembro de 2021. 